\title{
A Normative Exploration of the Link Between Development, Economic Growth, and Natural Risk
}

\author{
Stephane Hallegatte ${ }^{1}$ (D)
}

Received: 28 February 2017 / Accepted: 5 May 2017 / Published online: 1 June 2017

(C) The Author(s) 2017. This article is an open access publication

\begin{abstract}
The link between development and disaster losses is investigated in a normative framework. The paper innovates in modeling risk taking and its benefits. Under undemanding conditions, it is optimal for (i) disaster probability to decrease with income; (ii) the relative exposure to risk, i.e. the share of capital located in at-risk areas, to increase and the losses per event to increase faster than economic growth; and (iii) the risk, i.e. expected losses, to grow faster than income at low levels of development and slower than income at high levels of development. Increasing exposure to risk is both a consequence and a driver of economic growth and reducing disaster risk through reduced exposure is costly.
\end{abstract}

Keywords Development · Economic growth · Natural disasters $\cdot$ Risk

\section{Introduction}

Increased investments in disaster risk reduction have lead to a significant reduction in human casualties (Kahn 2005; Kellenberg and Mobarak 2008), but economic losses from natural disasters have been growing as fast or even faster than economic growth in many countries, see for instance Barredo (2009), Miller et al. (2008), Neumayer and Barthel (2010), Nordhaus (2010), Pielke et al. (2008), and Bouwer et al. (2007). This evolution can be explained by population and economic growth (richer countries have more assets that can be lost or damaged), and is magnified by an increasing exposure to risk, even in relative terms (an increasing share of assets is located in at-risk areas) (Schmidt et al. 2009; Neumayer and Barthel 2010; Bouwer 2011; Jongman et al. 2012; IPCC 2012). Migrations toward

Stephane Hallegatte

shallegatte@worldbank.org

1 The World Bank, Global Facility for Disaster Reduction and Recovery, 1818 H Street NW,

Washington DC, USA 
hurricane-prone areas can explain why hurricane losses are increasing more rapidly than GDP in the US (Pielke et al. 2008). Globally, there is a trend toward higher exposure to risk: between 1970 and 2010, global population grew by $87 \%$, but the population living in flood plains increased by $114 \%$ and in cyclone-prone coastlines by $192 \%$. The GDP exposed to tropical cyclones increased from $3.6 \%$ of total GDP to $4.3 \%$ over the same period (UNISDR 2011). At the country level, migration toward and investment within flood zones have led to an increase in exposure that is larger than national-level population and economic growth (see Pielke et al. 2008, in the US, and Jongman et al. 2014, in the Netherland).

These trends in disaster exposure and economic losses have been the topic of intense research. Previous investigations have focused on two questions.

A first line of research has tried to identify market failures or behavioral biases that would explain excessive risk taking. For instance, Camerer and Kunreuther (1989) and Hogarth and Kunreuther (1995) investigate how lack of information and transaction costs can affect decision-making. Tversky and Kahneman (1975), Kunreuther and Slovic (1978), and Thaler (1999) investigate behavioral biases in how people perceive and react to risks. Burby et al. (1991), Laffont (1995) and Michel-Kerjan (2010) study moral hazard issues linked to post-disaster support and ill-designed insurance schemes. Kousky et al. (2006) discuss the government decision-making process and find that benefit non-convexity can lead to multiple equilibria. Excessive risk taking has also been linked to institutions, such as inequality, corruption, ethnic fragmentation, coordination failure and governments' inability to commit (e.g., Kahn 2005; King 2006). These analyses at the micro level aim at explaining an excess in risk taking, and mostly assume that the current trends are the symptom of sub-optimal decision-making.

Another line of research uses normative approaches to investigate whether it can be rational (or even optimal) for a country to experience growing aggregate disaster losses (e.g., Lewis and Nickerson 1989; Kahn 2005; Kellenberg and Mobarak 2008; Schumacher and Strobl 2011). These analyses are performed at the macro-scale. They do not primarily investigate the possible biases and distortions in individual decision-making, but focus on aggregate (human or economic) losses. They conclude that the optimal evolution of disaster losses does not need to be a monotonic decrease, and identify situations in which disaster losses can increase over time, even in the absence of market failure or behavioral biases.

This paper expands on this latter research line, and especially the analysis by Kousky et al. (2006) and Schumacher and Strobl (2011), through the inclusion of the benefits from risk-taking in the analysis. ${ }^{1}$ It also questions the premise of the first research line, which assumes that observed risk taking is excessive and tries to identify the reasons for this excess. This paper relies on a simple normative model in which a benevolent social planner maximizes expected utility by choosing how much to invest in flood protection, how much to invest in at-risk areas, and how much to invest in safe areas. It assumes that decisionmakers are rational and perfectly informed and that moral hazard effects can be avoided (e.g., thanks to risk-based insurance premium).

The main contribution of this paper is to show that optimal relative exposure to risk generally increases with development (in other words, the optimal share of capital located in at-risk areas increases with income). Furthermore, the optimal increase in exposure dominates the increase in protection expenditures, and optimal average losses increase over time. They even grow faster than income at low levels of development and slower than income at high levels of development. Disaster losses can therefore increase over time, even without

\footnotetext{
${ }^{1}$ Here, risk taking is defined as investing in at-risk areas instead of safe areas.
} 
market failure, irrational behaviors, moral hazard, or other distortion (and with no change in climate conditions and hazard characteristics).

Even if optimally managed and without environmental changes, the model also suggests that natural disasters will become rarer but more destructive in the future. Biases in decisionmaking (e.g., moral hazard) may amplify this trend, but they are not necessary for aggregate disaster losses to increase (and even to increase more rapidly than economic growth). This result is relevant in spite of the simplifications in the model, since it shows that current trends in disaster losses do not need to be due to market failures or behavioral biases.

Reciprocally, the model suggests that increasing exposure to risk reinforces economic growth and increase the rate of growth. A consequence is that risk taking should not be indiscriminately suppressed and that reducing disaster risk through reduced exposure could affect negatively economic growth. This result echoes other papers emphasizing the benefits from risk taking. For example, people who lack access to proper tools to manage natural risk tend to spread risk over a large array of lower-risk activities and to reduce their investments, thereby reducing returns to assets and income. Smallholders plant low-return, low-risk crops and limit their investment in fertilizers to reduce their exposure to risk (Cole et al. 2013). In rural Zimbabwe, farmers who are exposed to risk own on average half as much capital as farmers who are not exposed (Elbers et al. 2007). Ex ante reductions in investments account for two-thirds of the difference; only one third stems from the actual destruction of capital because of shocks. Most of the impact of risk on well-being is thus through reduced investments, not through the damages and losses incurred when a hazard does materialize into an actual event.

The analysis proposed in this paper innovates compared with previous research because it provides an explicit modeling of both risk taking and protection investment, to characterize the two-way link between economic growth and disaster losses. In previous papers (e.g., Kousky et al. 2006; Kellenberg and Mobarak 2008; Schumacher and Strobl 2011), risk is only a negative thing against which "protective expenditures" are needed (using the term from Nordhaus and Tobin 1973). In these papers, the increase in exposure to natural disasters is only a consequence of population and economic growth. In the new framework proposed here, investing in risky areas is a conscious and well-informed choice, justified by the economic benefits that can be derived from taking risks. Examples of such benefits include: promoting international trade in areas with low transportation costs but exposed to flood risks (e.g., Gallup et al. 1998); generating agglomeration externalities in cities (Ciccone and Hall 1996; Ciccone 2002; World Bank 2008); generating environmental amenities (e.g., from sea views) and revenues from tourism. And increased exposure to risk can be an unavoidable by-product of productive investments (e.g., Cole et al. 2013; Elbers et al. 2007).

This innovation has major consequences on how natural risks are considered: here, risks need to be managed, and not always reduced, and there are two policy levers (exposure regulations and protection expenditures) instead of one in the rest of the literature (protection expenditures). This new framework helps understand why risk management is difficult and why so many risk management policies are poorly enforced and implemented (see examples in World Bank, 2013, Chapter 2). Poor records in risk management cannot be understood if the (aggregated) benefits from risk-taking are not accounted for explicitly.

The next section "Development and Natural Risks" describes the generic model and the conditions under which disaster losses increase with economic growth. "“Horizontal" and "Vertical" Capital Accumulation and Protection Costs" presents more detailed results for different specifications of protection costs, and "Trends in Disaster and Economic Growth" investigates special cases of production functions. "Numerical Application to New Orleans" 


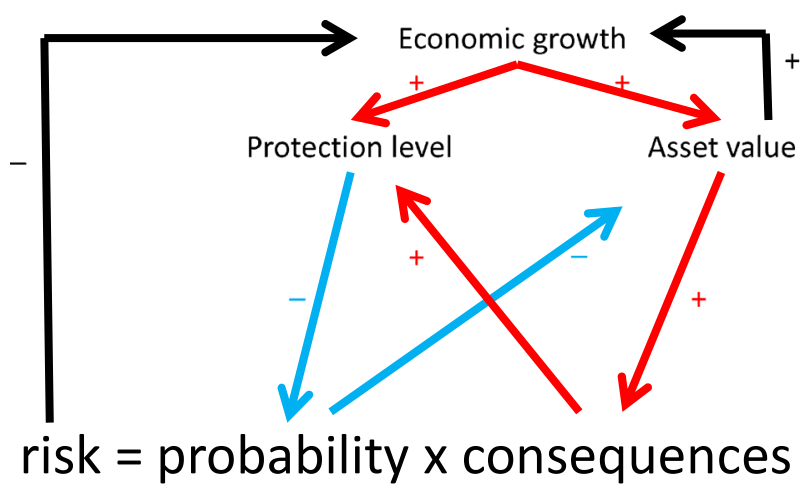

Fig. 1 The conceptual framework used in the paper

applies this model to New Orleans, demonstrating that reasonable parameter values lead to a situation in which economic growth increases exposure to risk and disaster losses. "Conclusion" concludes.

\section{Development and Natural Risks}

At an aggregated level, economic growth affects the average level of disaster losses (i.e., the risk level) through two main channels. First, higher income makes it possible to invest in better protections against disasters, therefore reducing the probability of a disaster (a protection effect). ${ }^{2}$ But higher income is also likely to increase the value of assets located in risky areas, and therefore to increase the consequences if a disaster occurs (a wealth effect). The impact of economic growth on risk - defined as the product of the probability and the consequences - is therefore ambiguous. And the system is made more complex by the interactions between these two channels: more protection reduces the disincentive to invest in risky areas and can magnify the wealth effect. And higher asset value in at-risk areas increases the incentive to protect the area, magnifying the protection effect. Exposure to risk influences economic growth, for instance because coastal development has revealed critical for export-led growth, and the overall level of risk feedback on economic growth through disaster losses. Figure 1 summarizes these different potential effects. The model represents in a highly idealized manner these different mechanisms.

\section{A General Economic Growth Framework}

We assume there are two categories of capital. Capital $R$ represents the capital related to activities that need to be (or benefit from being) located in areas that are potentially at risk of flooding. There are two categories of such capital. First, some activities directly depend on being in risky areas, such as ports that are located in coastal areas or river flood plains.

\footnotetext{
${ }^{2}$ Note that we are considering here the probability of a disaster, not of a hazard. While risk management cannot change the probability of a hurricane of a given strength, it can influence the probability that a hurricane is strong enough to cause damages. Other policies (e.g., climate change mitigation) can influence hazard probabilities by modifying climate conditions, but these policies are active over the very long term and are not considered in this paper.
} 
Second, positive concentration externalities make it profitable to invest in at-risk areas, even in sectors that do not depend directly on being at risk — such as finance in New York City to benefit from spill-overs from industries that need to be located in flood-prone areas (such as ports): (i) existing infrastructure for transportation, water, energy, and communication; (ii) large labor markets with access to skilled workers; and (iii) access to public services and amenities (art and culture, schools, university, etc.). Finally, increased exposure to risk can generate benefits from environmental amenities, directly (e.g., amenities from sea views) or indirectly (e.g., through tourism revenues) ${ }^{3}$

Capital $S$ represents the rest of economy, which can be located in safe locations without loss of productivity. These two capitals are inputs in the production function:

$$
Y=e^{\gamma t} F(R, S)
$$

where $t$ is time, $F$ is a production function and $\gamma$ is the exogenous growth in total factor productivity. ${ }^{4}$ Classically, we assume that $\partial_{R} F(R, S)>0 ; \partial_{S} F(R, S)>0 ; \partial_{R}^{2} F(R, S)<0$ and $\partial_{S}^{2} F(R, S)<0$ (decreasing returns).

The capital $R$ can be affected by hazards, like floods and windstorms. If a hazard is strong enough, it causes damages to the capital installed in at-risk areas, and can be labeled as a disaster. We assume that in that case, a fraction $X$ of capital $R$ is destroyed. ${ }^{5}$

Unlike for instance Kahn (2005) and Kellenberg and Mobarak (2008), we do not represent fatalities and casualties separately from economic losses in this simple model. But these human losses can be included in economic losses (through $X$ ), if (1) fatalities and casualties can be measured by an equivalent economic loss (the value of a statistical life), (2) the value of a statistical life increases proportionally with economic growth (see a discussion in Viscusi and Aldy 2003), and (3) population density is proportional to capital density and the population at risk increases like the capital at risk $R \cdot{ }^{6}$ Similarly, introducing indirect economic losses would not change the model if indirect losses are proportional to direct losses. ${ }^{7}$

Disasters (i.e. hazards that lead to capital destruction) have a probability $p_{0}$ of occurring every year, unless protection investments $C$ reduce this probability. ${ }^{8}$ These protection investments take many forms, depending on which hazard is considered. Flood protections include dikes and seawalls, but also drainage systems for coping with heavy precipitations in urban areas. Windstorm protections consist mainly in building retrofits and stricter building norms, to ensure that old and new buildings can resist stronger winds.

It is assumed that better defenses reduce the probability of disasters, but do not reduce their consequences. ${ }^{9}$ It is of course a simplification of the reality where risk management actions have an effect of probability of occurrence and on the vulnerability, i.e. the

\footnotetext{
${ }^{3}$ King (2006) aggregates all of these benefits as an amenity in the utility function. Here, these are represented in the production function.

${ }^{4}$ Technical change is assumed not to be biased toward one of the capitals $R$ and $S$.

${ }^{5}$ More investment in at-risk areas increases (proportionally) the cost of a disaster, but does not affect the probability of occurrence of a disaster.

${ }^{6}$ As discussed in Appendix A, human losses cannot be shared or transferred, with consequences on risk aversion.

${ }^{7}$ However, modeling and econometric analyses suggest a nonlinear relationship, especially for large-scale disasters (Hallegatte 2008; Loayza et al. 2009).

${ }^{8}$ Protection investments are modeled as annual expenditures but they could be equivalently modeled as a stock.

${ }^{9}$ This is equivalent to the self-protection of Ehrlich and Becker (1972).
} 
consequences if a disaster does occur. This simplification is however consistent with many types of defenses. For instance, seawalls can protect an area up to a design standard of protection, but often fail totally if this standard is exceeded; building norms allow houses to resist up to a certain wind speed, but when this wind speed is exceeded, houses need total rebuilding. ${ }^{10}$

Similarly to Kousky et al. (2006), better defenses are also more expensive, and the annual cost of defenses $C$ increases when the remaining disaster probability $p$ decrease. ${ }^{11}$ The function $C(p, R)$ is assumed twice differentiable, $C\left(p_{0}, R\right)=0$ (the probability of occurrence is $p_{0}$ in the absence of protections), $\partial_{R} C(p, R) \geq 0$ (it is equally or more expensive to protect more capital), $\partial_{p} C(p, R) \leq 0$ (the cost increases when the probability decreases), $\partial_{p}^{2} C(p, R) \geq 0$ and $C(0, R)=+\infty$ (the marginal cost is increasing and it is impossible to reduce the probability to zero) and $\partial_{p R}^{2} C(p, R) \leq 0$ (the cost of protecting more capital increases when the probability decreases).

Any given year, the economic surplus $\pi$ is given by:

$$
\pi=e^{\gamma t} F(R, S)-C(p, R)-L-r(R+S)
$$

where $r$ is the interest rate, $L$ is the loss from disasters, and is given by a random draw with probability $p$. If a disaster occurs, capital losses are equal to $X R$, i.e. a fraction $X$ of the capital located in the risky area is destroyed. ${ }^{12}$ In any given year, the expected loss $\mathbb{E}[L]$ is equal to $p X R$ and the expected output is equal to:

$$
\mathbb{E}[\pi]=e^{\gamma t} F(R, S)-C(p, R)-(r+p X) R-r S
$$

Note that in this equation, disaster losses appear as an additional cost of capital at risk, in addition to the interest rate $r .{ }^{13}$

\section{Optimal Choice of $p, R$, and $S$}

We assume that a social planner - or an equivalent decentralized decision-making process - decides which amounts of capital $R$ and $S$ are to be located in the risky and safe areas,

\footnotetext{
${ }^{10}$ This modeling choice is made without loss of generality, if there is no risk aversion. In this case, indeed, a change in the probability of occurrence or in the consequences is equivalent. The role of risk aversion is investigated in Appendix A.

${ }^{11}$ The probability $p$ here includes both the probability that an event exceeds protection capacities, and the defense failure probability, even for weaker events.

${ }^{12}$ Assuming that the owners of these assets are the one who lose from these losses, there is no moral hazard in the model.

${ }^{13}$ This equation can be interpreted as a case where reconstruction is completed instantaneously, by removing the value of disaster losses from production. In that case, the production net of reconstruction expenditure in case of a disaster is $F(R, S)-X R$, and expected output is given by Eq. 3. It can also be interpreted as a case where there is no reconstruction, and the production $F(R, S)$ is reduced to $F((1-X) R, S)$. In that case, and assuming $X$ is small enough for the linear approximation to hold, then the net present value of residual production $F((1-X) R, S)$ is equal to the net present value of the pre-disaster production level $F(R, S)$, reduced by the net present value of the output that would have been produced by the destroyed capital, which by definition is the value of the destroyed capital, i.e. $L=X R$. This formulation is also consistent with Eq. 3 . The impact of capital losses on output is discussed in more details in Hallegatte and Vogt-Schilb (2017).
} 
and the level of protection ( $p$ and $C(p, R)$ ) that is to be built. ${ }^{14}$ Her optimization program is: ${ }^{15}$

$$
\begin{aligned}
& \max _{p, R, S} \mathbb{E}[\pi] \\
& \text { s.t. } \leq p \leq p_{0}
\end{aligned}
$$

We assume first that there is no risk aversion and we assume that the expected surplus is maximized. From the social planner's perspective, doing so is acceptable if disaster losses remain small compared to aggregated income, consistently with the Arrow-Lind theorem for public investment decisions (Arrow and Lind 1970). As discussed in Mahul and Ghesquiere (2007), this theorem holds only if some conditions are met, including if disaster losses can be pooled among a large enough population (e.g., a large country), and with many other uncorrelated risks, i.e. in the presence of comprehensive insurance coverage or post-disaster government support, or if disaster losses can be smoothed over time thanks to savings and borrowing (i.e. self-insurance) or reinsurance. In other terms, the optimal pathways determined by this analysis are valid assuming that the social planner ensures that individual losses remain small thanks to temporal smoothing and redistribution or insurance across individuals. Appendix A investigates the case with risk aversion.

Definition 1 We define:

- The "risk-free scenario" as a scenario in which there is no risk, either because $p_{0}=0$ (no hazard), because $X=0$ (no vulnerability), or because $C(p, R)=0$ (costless protections). In the risk-free situation, there are still two capitals $R$ and $S$, but none of them is at risk.

- The "safe-development" scenario as a scenario where investment in at-risk areas is prohibited (e.g., by a strict zoning policy), such as $R=0$ (and no protection investment is needed so that $p=p_{0}$ and $\left.C\left(p_{0}, R\right)=0\right)$.

- The "risk-taking" scenario is a scenario where capital at risk $R$, safe capital $S$, and the probability of occurrence of a disaster $p$ are fixed optimally.

\footnotetext{
${ }^{14}$ This corresponds to the case of an open economy where the interest rate is fixed by the rest of the world and can be considered as exogenous by the social planner. Of course in practice the decision-maker cannot select $R, S$, and $p$ directly, but she can chose $I_{R}, I_{S}$, and $I_{p}$, the investments in at-risk capital, safe capital, and protection capital. The two problems are equivalent only if considering long timescales or situation close to the equilibrium. Also, Kousky et al. (2006) investigates the interesting case where decisions are sequential and the government decides of the protection level and private actors then decide how much to invest in risky areas.

${ }^{15}$ This model is more general than the model of Schumacher and Strobl (2011). In the latter, the only decision concerns protection investments that mitigate disaster consequences, and there is no benefit from taking risks and thus no trade-off between risk and return. This model also differs from Hallegatte (2011) in that it is more general on the shape of production and protection cost functions, and it introduces the interest rate to account for the consumption-investment trade-off. The model is somewhat similar to the one proposed in Kousky et al. (2006), but it differs in its taking into account two capitals, located in risky and safe areas. It therefore allows to consider the subsitution between safe and at-risk capitals, and to look at the benefits from investing is at-risk areas (compared with safe investments). The model is also more general than in King (2006), see in particular Appendix 1, because protection is not represented though a binary choice (protection or not; but it does not include political economy considerations.
} 
Assuming ${ }^{16} p<p_{0}$, first order conditions in the "risk-taking" scenario lead to the optimal values of $p, R$, and $S:{ }^{17}$

$$
\begin{aligned}
e^{\gamma t} \partial_{R} F(R, S)-\partial_{R} C-(p X+r) & =0 \\
e^{\gamma t} \partial_{S} F(R, S)-r & =0 \\
\partial_{p} C & =-X R
\end{aligned}
$$

While the marginal productivity of capital $S$ is $r$, the marginal productivity of capital $R$ is $r+p X+\partial_{R} C$, i.e. the cost of capital $r$ plus the capital losses due to disasters $p X$ plus the incremental cost of protection $\partial_{R} C$. The term $r+p X+\partial_{R} C$ is what we define as the hazard-adjusted cost of capital, and it is larger than the risk-free cost of capital, to account for natural risks. ${ }^{18}$

Since $p X>0, \partial_{R} C>0$, and $\partial_{R} F$ is decreasing, the first equation shows that the presence of risk $(X>0$ and $C>0)$ leads to a reduction in $R$.

Proposition 2.1 The presence of risk and the possibility to protect against it lead to a reduction in the capital that is located in the risky area, compared with the risk-free scenario.

Taking the derivative of Eqs. 5-7 with respect to time $t$, one gets:

$$
\begin{array}{r}
\gamma e^{\gamma t} \partial_{R} F+\left[e^{\gamma t} \partial_{R}^{2} F-\partial_{R}^{2} C\right] \partial_{t} R+e^{\gamma t} \partial_{R S}^{2} F \partial_{t} S=\left(X+\partial_{p R}^{2} C\right) \partial_{t} p \\
\gamma e^{\gamma t} \partial_{S} F+e^{\gamma t} \partial_{S}^{2} F \partial_{t} S+e^{\gamma t} \partial_{R S}^{2} F \partial_{t} R=0 \\
\partial_{t} p \partial_{p}^{2} C=-\left(X+\partial_{p R}^{2} C\right) \partial_{t} R
\end{array}
$$

Equation 10 shows that if $\left(X+\partial_{p R}^{2} C\right)<0$, then an increase in at-risk capital (everything else being unchanged) leads to a decrease in protection (i.e. an increase in the probability of occurrence), because the cost of protection then increases more rapidly with $R$ and $p$ than the avoided disaster losses. If $X+\partial_{p R}^{2} C=0$, then the probability of occurrence is independent of $R$, and thus constant over time even in the presence of economic growth.

If we have

$$
\left(X+\partial_{p R}^{2} C\right)>0
$$

then having more capital at risk leads to an increase in protection, and the probability of occurrence $p$ and the amount of capital at risk $R$ evolve in opposite directions.

This condition can be interpreted in economic terms: if it is not met, then increasing the amount of capital at risk increases the cost of protection more than the benefits from doing so; in that case, more capital at risk reduces the incentive to protect. This can be the case if the new capital becomes more and more difficult (and thus costly) to protect, i.e. where productive-capital investments should be made assuming that no additional protection will be provided. It is also the case where protection levels will decrease over time. Considering

\footnotetext{
${ }^{16}$ If $p=p_{0}$, then there is no protection in place - because protections are too expensive - and the situation is highly simplified: disaster risk reduces by a fixed fraction the productivity of the capital at risk. Classically, this reduces the amount of such capital without influencing its growth rate on the balanced growth pathway.

${ }^{17}$ As stressed in Kousky et al. (2006), some functional forms can lead to multiple equilibria. Here the analysis focuses on marginal changes around the unique or multiple equilibria.

${ }^{18}$ Equivalently, one can define the hazard-adjusted marginal productivity of capital as the marginal productivity of capital reduced by the cost of protection and disaster capital losses: $e^{\gamma t} \partial_{R} F(R, S)-\partial_{R} C-$ $p X$.
} 
the larger protection level provided in rich countries than in poor countries (see an analysis on 136 coastal cities in Hallegatte et al. 2013) and the global trend toward better protection levels, it seems however that in most locations having more capital at risk leads to better protection and that condition (11) is often met. Assuming that protection costs increase linearly with the area to protect, it is also the case under the assumption that new investments are made at an increasing density (see a discussion in "“Horizontal" and "Vertical" Capital Accumulation and Protection Costs"). In the following, we assume that this condition is met.

Replacing $\partial_{t} p$ in Eq. 8 and replacing $e^{\gamma t} \partial_{R} F$ by $\left(r+p X+\partial_{R} C\right)$ yields:

$$
\partial_{t} R=\frac{\gamma\left(r\left(1-\frac{\partial_{R S}^{2} F}{\partial_{S}^{2} F}\right)+p X+\partial_{R} C\right)}{-e^{\gamma t}\left(\partial_{R}^{2} F-\frac{\left(\partial_{R S}^{2} F\right)^{2}}{\partial_{S}^{2} F}\right)+\partial_{R}^{2} C-\frac{\left(X+\partial_{p R}^{2} C\right)^{2}}{\partial_{p}^{2} C}}
$$

Since $\frac{\partial_{R S}^{2} F}{\partial_{S}^{2} F}<1$, the capital at risk increases over time when:

$$
-e^{\gamma t}\left(\partial_{R}^{2} F-\frac{\left(\partial_{R S}^{2} F\right)^{2}}{\partial_{S}^{2} F}\right)>-\partial_{R}^{2} C+\frac{\left(X+\partial_{p R}^{2} C\right)^{2}}{\partial_{p}^{2} C}
$$

To interpret this inequality, we can disregard for now the interactions between $R$ and $S$ (i.e. assuming that $\partial_{R S}^{2} F=0$ ) and assume that protection costs are independent of $R$ (i.e. $\partial_{R}^{2} C=0$ and $\partial_{p R}^{2} C=0$ ). In this case, the capital at risk increases over time when:

$$
-e^{\gamma t} \partial_{R}^{2} F>\frac{X^{2}}{\partial_{p}^{2} C}
$$

This inequality is verified if the marginal productivity of the capital at risk decreases more rapidly with $R$ than the marginal cost of protection increases with $p$. In this situation, the probability of disaster decreases with economic growth.

Proposition 2.2 If $X+\partial_{p R}^{2} C>0$ and if the production function is sufficiently concave - or if the protection costs are sufficiently convex - then economic growth leads to an increase in capital at risk (i.e. an increase in losses when a disaster occurs or in "loss per event"), and a decrease in the probability of occurrence. If the production function is less concave, then economic growth leads to a decrease in capital at risk and an increase in disaster probability.

It is interesting and counter-intuitive to note that in cases where returns are decreasing rapidly in the at-risk area, capital at risk is more likely to increase over time. Similarly, it is noteworthy that where protection costs are increasing rapidly with the desired level of protection (i.e. in place that are more difficult to protect), capital at risk is more likely to increase over time. These surprising results arise from the difference between the effect of risk on the level of capital at risk (see Proposition 1) and the effect of risk on the growth rate of capital at risk. Basically, when returns are decreasing more rapidly or when protection costs increase more rapidly, the level of capital at risk is lower, as is expected, but its growth rate is higher.

It is also remarkable that this result does not require any assumption about the relative productivity of capital in at-risk and safe areas. In other terms, we do not need to assume that capital is "more productive" is at-risk areas. We only need to make the assumption that 
investments in safe areas are not perfect substitute for investments in risky-areas, which is a weaker assumption that sounds realistic (for instance, shipping infrastructure cannot be built in areas that are not exposed to coastal floods).

Note that if development leads to a reduction in capital at risk $R$ and an increase in $p$, then at one point the economy reaches a situation where there is no protection and $p=p_{0}$. In such a situation, capital at risk $R$ grows at the same rate as in the risk-free situation.

The capital $R$ in the risk-free scenario is referred to as $R^{s}$, and its evolution is:

$$
\partial_{t} R^{S}=\frac{\gamma\left(r\left(1-\frac{\partial_{R S}^{2} F}{\partial_{S}^{2} F}\right)\right)}{-e^{\gamma t}\left(\partial_{R}^{2} F-\frac{\left(\partial_{R S}^{2} F\right)^{2}}{\partial_{S}^{2} F}\right)}
$$

Assuming that the capital $R$ increases with economic growth, i.e. that condition (13) is verified, then the comparison of Eqs. 12 and 15 explains how the protection influences the evolution of capital:

- The term $p X+\partial_{R} C$ in the numerator is the impact of risk and protection marginal costs on marginal productivity; it increases the numerator and accelerates the absolute growth in $R$.

- The term $\partial_{R}^{2} C$ in the denominator is the decreasing or increasing return on protection; if the returns on protection are constant (e.g. $C(p, R)=R C(p)$ or $C(p, R)=C(p))$, then this term does not exist; if the returns are decreasing (i.e. costs are convex and $\partial_{R}^{2} C>0$ ), then this term increases the denominator and slows down the growth in $R$; if the returns are increasing, then the growth in $R$ is accelerated.

- The term $-\frac{\left(X+\partial_{p R}^{2} C\right)^{2}}{\partial_{p}^{2} C}$ in the denominator is the impact of the change in protection that is provided if more capital is installed in at risk areas (if the probability of occurrence is fixed, this term does not appear). Since $\partial_{p}^{2} C>0$, this term is negative and reduces the denominator and thus accelerates the growth in $R$.

\section{Trend in average annual losses}

Average economic losses due to disasters are equal to $\mathbb{E}[L]=p X R$. Under condition (11), the probability of a disaster $(p)$ and the losses in case of disaster $(X R)$ evolve in different direction and the impact on risk (i.e. on average losses $\mathbb{E}[L]$ ) is ambiguous. The time evolution of risk can however be written as:

$$
\partial_{t} \mathbb{E}[L]=X R \partial_{t} p+p X \partial_{t} R
$$

It can be rewritten:

$$
\partial_{t} \mathbb{E}[L]=\partial_{t} p\left[\partial_{p} C-\frac{p \partial_{p}^{2} C}{1+\frac{\partial_{p R}^{2} C}{X}}\right]
$$

Since $\partial_{p} C<0$ and $\partial_{p}^{2} C>0$, and under condition (11), then $\mathbb{E}[L]$ and $p$ evolve in opposite directions.

Proposition 2.3 If $X+\partial_{p R}^{2} C>0$, then average annual disaster losses increase when the probability of occurrence decreases over time.

This result highlights the need to consider the combination of exposure $(R)$ and probability $(p)$ to investigate risks. In particular, a reduction in the probability of occurrence does 
not mean that average losses decrease; on the opposite, this general analysis suggests that under mild conditions a decrease in the probability of occurrence leads to an increase in average losses, because of the increase in capital at risk.

Importantly, this analysis illustrates that protection reduces the hazard (the probability of occurrence of an event), but its impact on risk is more complex, because it also increases exposure (here, the capital at risk $R$ ). As a result, protection transfers part of the risk from one kind of risk (frequent and low-cost events) to another kind (exceptional and high-impact events), a process already stressed in Etkin (1999).

\section{"Horizontal" and "Vertical" Capital Accumulation and Protection Costs}

We already made assumptions on the shape of $C(p, R)$, but it is useful to explore two extreme cases for the dependence of $C(p, R)$ to $R$.

In a first case, we can consider a coast or a river, where additional capital investments are conducted at a fixed density and are thus using additional land, which in turn requires additional protection. In such a case, the protected area increases proportionally with the invested capital in the risky zone, and $C(p, R)=R \tilde{C}(p)$. For instance, this is the case in some parts of France, where population density is low and flood exposure increases mainly through the construction of individual houses, at low density. This situation can be labeled "horizontal" or "area-increasing" capital accumulation.

In a second case, we consider a given risky area, which is protected against coastal floods and where investment takes place. In such a case, the risky and protected area does not increase with investments, and the cost of protection is independent of the amount of protected capital: $C(p, R)=\tilde{C}(p)$. This is notably the case where additional investments take place through higher concentration and density, on a given area. Examples of such places are the Netherlands, New Orleans, or Manhattan in New York City. This situation can be labeled "vertical" or "density-increasing" capital accumulation.

Let us explore the consequence of these two assumptions on flood risks.

\section{Horizontal Accumulation}

We assume first that the protection cost function has the form $C(p, R)=R \tilde{C}(p)$. The marginal cost and benefit of protection are equal (7), which means $R \partial_{p} \tilde{C}(p)=-X R$. Therefore, $p$ is independent of $R$ and constant over time.

Deriving the previous equation with respect to $R$ gives $X+\partial_{p R}^{2} C=0$, and we can rewrite Eq. 5 as:

$$
e^{\gamma t} \partial_{R} F(R, S)=\overbrace{\tilde{C}(p)+p X+r}^{r^{\prime}}
$$

Since $\tilde{C}(p)$ is constant and positive, the hazard-adjusted marginal productivity $r^{\prime}$ is also a constant, larger than $r$. In this case, $R$ evolves like the safe capital $S$, but with a larger interest rate $\left(r^{\prime}\right.$ instead of $r$ ). Since marginal productivity needs to be larger, the amount of capital is lower in the presence of decreasing returns $\left(R<R^{S}\right)$, i.e. risk leads to a reduction in capital $R$. With classical production functions (CES or Cobb-Douglas) and neutral technological change, the capital at risk $R$ increases at the same rate as economic growth. Since $p$ is constant, $\partial_{t} \mathbb{E}[L]=p X \partial_{t} R$, and average annual losses grow at the same rate as capital at risk and as risk-free economic growth. 
Proposition 3.1 In horizontal-accumulation locations - i.e. where flood exposure increases because the developed area at risk is expanded and where protection costs increase therefore proportionally with protected capital — rational decision-making leads to annual flood losses growing at the same rate as economic growth, with a constant flood probability, regardless of how protection costs vary with the residual probability of occurrence. In that case, economic growth rates are the same in the "safe-development" and in the "risk-taking" scenarios (but production is higher in the latter case).

\section{Vertical Accumulation}

We then assume that $C(p, R)=\xi p^{-v}+C_{0}$. Assuming $p<p_{0}$, we can use Eq. 7 to find:

$$
p=\left(\frac{R X}{v \xi}\right)^{-\frac{1}{1+v}}
$$

We have $\partial_{p R}^{2} C=0$, and thus $X+\partial_{p R}^{2} C>0$ if there is risk, so that condition (11) is always verified. As a consequence, we know that $p$ and $R$ evolve in opposite directions: if capital increases (resp. decreases), the protection is strengthened (resp. weakened) and disaster probability decreases (resp. increases). We are in the situation where $p$ decreases and $R$ increases when condition (13) is verified, and it can be rewritten:

$$
-e^{\gamma t}\left(\partial_{R}^{2} F-\frac{\left(\partial_{R S}^{2} F\right)^{2}}{\partial_{S}^{2} F}\right)>\frac{X^{2} p^{v+2}}{v(v+1) \xi}
$$

Also, we know from the general analysis that $\partial_{t} \mathbb{E}[L]$ is positive and average disaster losses are increasing over time.

Proposition 3.2 In locations where flood exposure rises as a result of increased density in a given protected area (e.g., New Orleans), rational decision-making results in a continuous increase in annual flood losses, when flood probability decreases over time.

\section{Intermediate Cases}

If protection increases with the amount of capital, but with increasing returns, we can assume that $C(p, R)=\xi R^{c} p^{-v}+C_{0}$, where $0 \leq c<1$. In that case, we still have the optimal probability of occurrence of a disaster prescribed by Eq. 19.

The calculation of $\partial_{p R}^{2} C$ gives:

$$
\partial_{p R}^{2} C=-\xi v c p^{-(v+1)} R^{c-1}
$$

Replacing $p$ in Eq. 22 using Eq. 19, we get

$$
\partial_{p R}^{2} C=-c
$$

which means that condition (11) is verified when $X$ is larger than $c$, i.e. when the share of capital at-risk that is destroyed in case of disaster is larger than the exponent of the amount of capital in the protection cost function. The condition is thus satisfied if the capital is highly vulnerable ( $X$ is large), or if protection costs increase slowly with the amount of capital at risk (investments are done through increased density more than through larger developed areas; $c$ is small).

In these cases where condition (11) is verified, we know that the probability of occurrence $p$ and the consequences in case of disaster (losses per event, $X R$ ) are evolving in 
opposite directions, and that average annual losses are increasing over time. To go further, assumptions are needed on the shape of the production function. This is what is investigated in the next section.

\section{Trends in Disaster and Economic Growth}

In this section, we keep the "vertical accumulation" assumption, i.e. $C(p, R)=\xi p^{-v}+C_{0}$. We assume that capital at risk $R$ and safe capital $S$ are separable inputs in the production function $(F(R, S)=f(R)+g(S))$, and that $f(R)=\lambda R^{\mu}$ and $g(S)=\alpha \lambda S^{\mu}$ (the CobbDouglas case is explored in Appendix B).

\section{The Safe-Development Scenario}

Let us consider first the case where a strict zoning policy prevents any development in at-risk areas, such that $R=0$. We can solve Eq. 6:

$$
S=(\alpha \lambda \mu)^{\frac{1}{1-\mu}} e^{\frac{\gamma t}{1-\mu}} r^{\frac{-1}{1-\mu}}
$$

With this shape of production function and no risk-taking, a productivity growth at rate $\gamma$ leads to a growth in safe capital at a rate $\gamma_{S}=\frac{\gamma}{1-\mu}$. Economic output also grows at a rate $\gamma_{g}^{S}=\gamma_{S}=\frac{\gamma}{1-\mu}$. This is also the growth rate in a situation where there is no risk (the risk-free scenario), i.e. $R^{s}$ and $S$ grow at the rate $\frac{\gamma}{1-\mu}$.

\section{The Risk-Taking Scenario}

We now assume that $R$ and $S$ are chosen optimally. With $p=\left(\frac{R X}{\nu \xi}\right)^{-\frac{1}{1+\nu}}$, we can rewrite Eq. 5:

$$
e^{\gamma t} \lambda \mu R^{\mu-1}=r+p X=r+X\left(\frac{X}{v \xi}\right)^{-\frac{1}{1+v}} R^{-\frac{1}{1+v}}
$$

This equation cannot be solved analytically, but two extreme cases - at low and high levels of development — can be analyzed.

\section{Low Development Level}

At a low development level, total factor productivity is low, the amount of capital is small (i.e., $R$ is small) and the probability of occurrence of a disaster is large ( $p$ is large). ${ }^{19}$ In such an extreme situation, the capital interest rate $r$ is small in the at-risk area compared with the flood-related capital losses $p X$, and Eq. 24 can be simplified by removing $r$, leading to the solution:

$$
R(t)=R_{0} e^{\gamma_{R} t} \text { with } \quad \gamma_{R}=\frac{\gamma}{\frac{v}{1+\nu}-\mu}
$$

\footnotetext{
${ }^{19} \mathrm{We}$ assume here that $p_{0}$ is large, i.e. that the area-at-risk has a large flood probability in absence of protection, and that $p<p_{0}$. If productivity is so low that $p=p_{0}$, then $p X$ can be replaced by $p_{0} X$, which is independent of $R$. Then, Eq. 24 can be simplified by replacing its right-hand-side by $r+p_{0} X=r^{\prime}$. In this situation, the capital at risk is lower than in absence of risk $\left(R<R^{s}\right)$, but it grows at the same rate. When development increases productivity, there is a time when protection is such that $p<p_{0}$, and the following calculation holds if $p_{0}$ is large enough.
} 


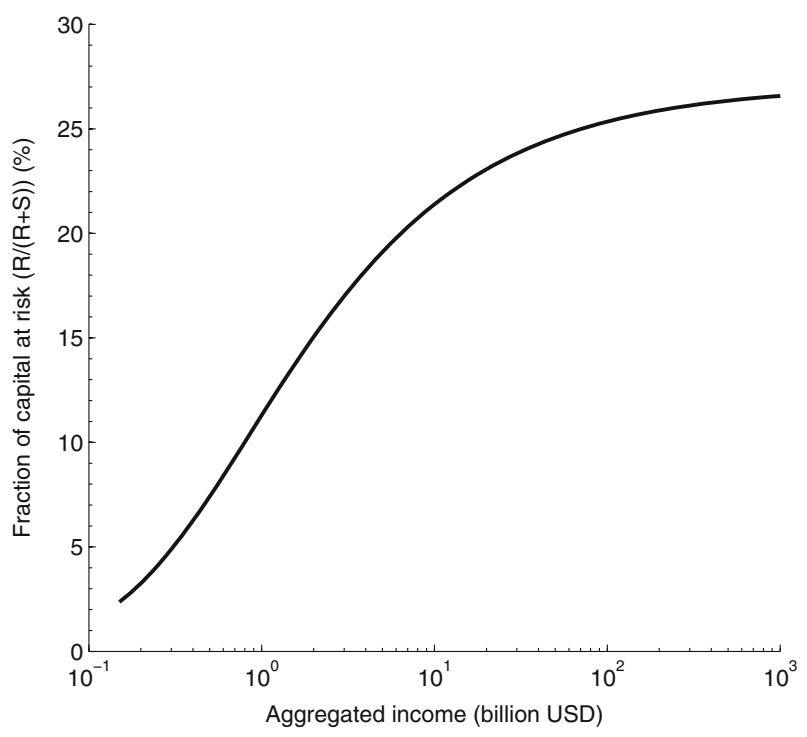

Fig. 2 Evolution of the "fraction at risk", i.e. the share of capital at risk $R$ in total capital $R+S$, as a function of time. The fraction at risk increases with development, until it stabilizes at a high development level. Calculations use numerical values from New Orleans (see "Numerical Application to New Orleans") and $\alpha=2$

In the situation in which protection improves over time, $\mu<\frac{v}{1+v}$, the growth rate of capital at risk is $\frac{\gamma}{\frac{\nu}{1+\nu}-\mu}$, which is always larger than $\frac{\gamma}{1-\mu} \cdot{ }^{20}$ In this case, therefore, the capital at risk grows more rapidly than the safe capital. The relative vulnerability of the economy can be measured by the amount of disaster losses when a disaster occurs divided by income or by the "fraction at risk", i.e. the share of capital at risk $R$ in total capital $R+S$. This vulnerability is increasing over time, as shown in Fig. 2. Interestingly, the growth in capital at risk is more rapid when $v$ is smaller, i.e. when the convexity of protection costs is lower and protection costs increase slowly with the protection level.

Average losses $p X R$ have a growth rate equal to:

$$
\gamma_{L}=\frac{\gamma}{1-\mu \frac{1+v}{v}}
$$

In the situation in which protection improves over time, $\mu<\frac{v}{1+v}$, average losses increase over time, and they increase more rapidly than $\frac{\gamma}{1-\mu}$ and thus more rapidly than risk-free economic growth, i.e. the growth rate of $R^{S}$ and $S$, and more rapidly than output in a safedevelopment scenario. ${ }^{21}$

\footnotetext{
${ }^{20}$ If $\mu>\frac{v}{1+v}, R$ decreases and $p$ increases over time, until it reaches $p_{0}$, i.e. the absence of protection. Then, capital at risk grows at the same rate as economic growth in the risk-free and safe-development scenarios.

${ }^{21}$ Note that this case is equivalent to the case explored in Hallegatte (2011) where the total amount of capital $(R+S)$ is fixed at an exogenous level $K$, and is independent of the risk level (which is equivalent to $r=0$ provided that $R \leq K$ ). It is a situation in which there is no consumption-investment trade-off, and in which the capital at risk can keep increasing more rapidly than growth, until all the capital is located in the risky area. What follows shows that accounting for the consumption-investment trade-off changes significantly the results at a high level of development.
} 
The economic surplus generated by the at-risk capital is $\mathbb{E}\left[\pi_{R}\right]=e^{\gamma t} F(R, S)-$ $C(p, R)-(r+p X) R$. It is growing at a rate $\gamma_{g}^{R}$, which is the same as for losses, i.e. $\gamma_{g}^{R}=\gamma_{L}$. Since the surplus generated by the safe capital grows at a rate $\gamma_{g}^{S}<\gamma_{g}^{R}$, the surplus generated by both capitals grow at a rate $\gamma_{g}$ that is between $\gamma_{g}^{S}$ and $\gamma_{g}^{R}$. Its value in this interval depends on the spatial scale of analysis: if considering a large region that is largely safe, then $\gamma_{g}$ will be close to $\gamma_{g}^{S}$; if considering a small region that is largely at-risk, then $\gamma_{g}$ will be close to $\gamma_{g}^{R}$.

The economic surplus generated by both capital grows at a rate $\gamma_{g}$ that is therefore higher in the risk-taking scenario than in the safe-development scenario (and in the risk-free scenario). It means that it is preferable to invest in at-risk areas, to pay for disaster protection, and to lose part of the capital at risk because of disasters than to ban all development in at-risk areas. Increasing exposure to risk is a driver of economic growth (even though the presence of risk leads to a lower output, see Proposition 1).

In this context, the elasticity of the losses per event to income is equal to $\gamma_{R} / \gamma_{g}>$ $\gamma_{R} / \gamma_{g}^{R}=(1+v) / v>1$ : losses per event are increasing more rapidly than income. Average losses are increasing at the same rate as local income from capital at-risk $\gamma_{L}=\gamma_{g}^{R}$ and more rapidly than total income $\gamma_{L}>\gamma_{g}$. The elasticity of average disaster losses to national income should be larger than one.

\section{High Development Level}

At a high development level, capital productivity is large, and the amount of capital at risk $R$ is large. ${ }^{22}$ As a consequence, the probability of occurrence $(p)$ is small. In such an extreme situation, the capital interest rate $r$ is large compared with flood-related capital losses $p X$, and Eq. 24 can be simplified by removing $p X$, leading to a growth rate in capital at risk equal to:

$$
\gamma_{R}=\frac{\gamma}{1-\mu}
$$

At a high level of development, when disaster probability is very low, the capital at risk grows at the same rate as economic growth in the safe-development scenario or in the riskfree scenario. The fraction at risk stabilizes at high income levels, as shown in Fig. 2. In this case, average losses $p X R$ have a growth rate equal to:

$$
\gamma_{L} \underset{t \rightarrow+\infty}{\longrightarrow} \frac{\gamma}{1-\mu} \frac{v}{(1+v)}
$$

In that case, the different terms of the economic surplus from at-risk capital $(\mathbb{E}[\pi]=$ $\left.e^{\gamma t} F(R, S)-C(p, R)-(r+p X) R\right)$ are growing at different rates. The production $e^{\gamma t} F(R, S)$ and capital cost $r R$ are growing at a rate $\frac{\gamma}{1-\mu}$. The protection costs and average losses $p X R$ are growing at a rate $\frac{\gamma}{1-\mu} \frac{v}{1+v}$, i.e. more slowly than production. When productivity tends to infinity, the economic surplus from capital at-risk is growing at the rate $\gamma_{g}^{R}=\frac{\gamma}{1-\mu}$, i.e. at the rate of economic growth from safe capital, and at the economic growth rate in the safe-development scenario. Total economic output (from both capitals) is also growth at the same rate: $\gamma_{g}=\frac{\gamma}{1-\mu}$.

\footnotetext{
${ }^{22}$ Using a reductio ad absurdum argument, it is easy to show from Eq. 24 that $R$ tends toward infinity when productivity grows. Assume that $R$ is bounded when $t \rightarrow+\infty$. In this case, the left-hand-side of Eq. 24 tends toward infinity when $t$ increases, so the right-hand-side has to do the same. In that case, $r$ becomes negligible over time, and the solution of Eq. 24 tends toward Eq. 25, which is not bounded when $t \rightarrow+\infty$. This is in contradiction with our initial hypothesis.
} 
Average annual losses are thus growing less rapidly than economic growth $\left(\gamma_{L}<\gamma_{g}\right)$, but they never decrease in absolute terms. Furthermore, the growth rate in annual disaster losses is equal to economic growth multiplied by a "protection factor" $(v /(1+v))$, which depends only on the shape of the protection costs and is lower than one. The protection factor is also the income elasticity of average disaster losses (in a given region, for a given hazard). It should not be confused with the income elasticity of the losses per event, which is equal to one in that case.

\section{Development and Disaster Trends}

Results are summarized in Table 1. Appendix B shows that these results remain unchanged if $R$ and $S$ are two production factors in a Cobb-Douglas function. This analysis leads to three conclusions, concerning the trends in capital at risk, average annual losses, and economic surplus.

Proposition 4.1 If (i) capital at risk and safe capital can be separated in the production function or are two factors in a Cobb-Douglas function, (ii) protection costs are convex with respect to the amount of capital to protect, and (iii) capital returns are decreasing more rapidly than a threshold that depends on the convexity of protection costs with respect to the disaster probability of occurrence (i.e. if $\mu<v /(1+v)$ ), then economic losses in case of disaster (or the loss per event, $X R$ ) grow more rapidly than economic growth. Their rate of growth converges toward the rate of economic growth as development proceeds. The relative vulnerability of the economy (the "fraction at risk") is increasing over time.

Proposition 4.2 The average annual disaster losses follow a bell-shaped curve relative to income: average disaster losses are growing faster than income (and faster than income in a safe-development scenario) at low stages of development. Average disaster losses keep growing in absolute terms, but more slowly than income, at higher productivity levels. At a high productivity level, the growth rate of annual losses is the economic growth rate reduced by a "protection factor" that depends only on the convexity of protection costs.

Proposition 4.3 The presence of risk reduces the economic surplus. However, because of increasing exposure to risk, the rate of economic growth (endogenously determined in the model) is higher in a risk-taking scenario than in a safe-development scenario. Increasing relative exposure to risk makes the rate of economic growth higher than what can be expected from productivity growth only.

Note that capital does not need to be "more productive" in at-risk areas for the capital at risk to increase more rapidly than income (as was assumed in Hallegatte 2011). A growing

Table 1 Growth rate of economic output, losses per event (and capital at risk), and average losses, in the safe-development scenario and in two extreme cases for the risk-taking scenario

\begin{tabular}{llll}
\hline Growth rate of... & $\begin{array}{l}\text { Safe-development } \\
\text { scenario }\end{array}$ & $\begin{array}{l}\text { Risk-taking scen. } \\
\text { (low development) }\end{array}$ & $\begin{array}{l}\text { Risk-taking scen. } \\
\text { (high development) }\end{array}$ \\
\hline Economic output $\left(\gamma_{g}\right)$ & $\frac{\gamma}{1-\mu}$ & $\frac{\gamma}{1-\mu}<\gamma_{g}<\frac{\gamma}{1-\mu \frac{1+v}{v}}$ & $\frac{\gamma}{1-\mu}$ \\
Losses per event $\left(\gamma_{R}\right)$ & - & $\frac{\gamma}{1+v}-\mu$ & $\frac{\gamma}{1-\mu}$ \\
Annual average losses $\left(\gamma_{L}\right)$ & - & $\frac{\gamma}{1-\mu \frac{1+v}{v}}$ & $\frac{\gamma}{1-\mu} \frac{v}{(1+v)}$ \\
\hline
\end{tabular}


trend in the ratio of average annual losses to income can be rational if the production function exhibits decreasing returns and depends on two imperfectly-substitutable categories of capital ( $R$ and $S$ ), where $R$ is related to activities located in risk-prone areas. In this case, there is an incentive to invest in at-risk areas to benefit from high marginal returns at low capital levels. The policy implications of this result are discussed in the conclusion.

\section{Numerical Application to New Orleans}

To illustrate how these results would translate into pathways of exposure and risk in a realworld case, this section proposes an illustration on the case of New Orleans and its exposure to coastal floods from hurricanes' storm surge. The very simple model does not pretend to provide a quantification of the optimal risk level in the city or a normative estimate of how the risk should evolve or how much should be invested. Instead, this section is an illustration of the fact that realistic parameter values - calibrated on other, more sophisticated analyses - are consistent with the propositions discussed earlier in this paper. It shows that the conditions under which these propositions are valid are not extreme or unlikely, but consistent with realistic orders of magnitudes.

\section{Assumptions and Parameters}

We apply the simple model proposed in this paper with the following numerical assumptions, based on previous studies:

- The capitals are separable. The capital $R$ is located in the flood-prone area of New Orleans, and $S$ is the capital located in safe areas in the rest of the region or the country. The interest rate is $r=5 \%$.

- The area is fixed, and the protection costs depend only on the probability of occurrence $p$, not on the amount of capital to protect: $C(p, R)=\xi p^{-v}+C_{0}$. In that case, condition (11) is always verified, and $p$ and $R$ evolve in opposite directions.

- In absence of protection, the city would be flooded every year $\left(p_{0}=1\right)$.

- The cost of protecting New Orleans against category-3 storms is about $\$ 3$ billion in investments, and we assume a $10 \%$ annual maintenance cost; the probability of such a storm is one in 50 years. The annualized protection cost is $C(1 / 50)=\$ 450$ million per year, taking into account the cost of capital and maintenance costs.

- Protecting New Orleans against category-5 hurricane floods would cost about $\$ 30$ billion, with a $10 \%$ annual maintenance cost. The probability of such a storm is one in 200 years, so that $C(1 / 200)=\$ 4.5$ billion per year. ${ }^{23}$

These assumptions could be subject to discussion, but they provide an order of magnitude for the cost of protecting the city. Using these assumptions, we have:

$$
C(p)=\xi\left(p^{-v}-p_{0}^{-v}\right),
$$

with $p_{0}=1, v=1.66$, and $\xi=6.8 \cdot 10^{-4}$.

\footnotetext{
${ }^{23}$ State officials estimated the cost of Category 5 protection between $\$ 2.5$ and $\$ 32$ billion (Carter 2005; Revkin and Drew 2005; Schwartz 2005). More recent and detailed estimates by Louisiana Coastal Protection and Restoration (LACPR, led by the U.S. Army Corps of Engineers) reach even larger values.
} 
For New Orleans, we assume that $50 \%$ of capital at-risk is lost in the case of flooding. ${ }^{24}$

The production function is $Y=e^{\gamma t} F(K)=\lambda e^{\gamma t} R^{\mu}$, with $\mu=0.3$ and $\gamma=0.015$ (total factor productivity grows by $1.5 \%$ per year). The risk-free growth rate, i.e. the growth in the capital $S$ located in safe areas in the rest of the country, is $\frac{\gamma}{1-\mu} \approx 2.1 \%$ per year.

The variable $Y$ is the local GDP in the flood-prone areas of New Orleans. With an exposed population of 500,000 people, and a GDP per capita of $\$ 24,000$ (in 2009), the exposed GDP in the city is $\$ 12$ billion. To estimate $\lambda$, we numerically solve Eq. 24 to find $R$ as a function of $\lambda$, and we chose $\lambda$ so that the income in absence of disaster is $Y=\lambda R^{\mu}=\$ 12$ billion (in economic data, protection expenditures are included in income). The value is $\lambda=3.53$.

\section{Results}

We find that the optimal capital at risk in New Orleans is $R=\$ 59$ billion, i.e. about 5 times the local income. ${ }^{25}$ Losses in case of flood would be about $\$ 30$ billion, which is consistent with data for the flood due to Katrina (removing losses due to wind) (RMS 2005). The optimal protection level reduces the probability of occurrence of a flood to $2.2 \%$ per year, i.e. a return period of 45 years. This probability is close to the likelihood of a category- 3 hurricane, i.e. the current protection level in the city. Model results are thus largely consistent with the current situation in New Orleans. ${ }^{26}$

Then, we numerically solve Eq. 24 for a series of $t$. We find that, thanks to increased exposure to risk, the economic surplus $\pi$ is growing at a rate $2.2 \%$, i.e. $0.1 \%$ more rapidly than in a safe-development scenario (where income grows by $2.1 \%$ per year). We also find that $R$ is growing at a rate of $2.4 \%$, which means that losses per event are growing by $2.4 \%$ per year, i.e. $0.2 \%$ more rapidly than income. Average annual losses due to floods are growing at a $1.5 \%$ rate, i.e. slower than income.

In New Orleans, a rational decision-maker would thus make average disaster losses increase less rapidly than local economic growth (1.5 vs. $2.2 \%)$, but would increase capital at risk and losses per event more rapidly than local income (2.4 vs $2.2 \%$ ) and more rapidly than safe-development growth (2.4 vs $2.1 \%$ ). It means that the New Orleans region evolves toward fewer disasters with consequences that are growing relative to local and national income, leading to an increased need for recovery and reconstruction support.

One can also investigate how this result depends on the local income in New Orleans (and thus on total factor productivity), assuming that everything else remains unchanged (including protection costs $C(p)$ and the fraction of capital at risk lost in case of flood $X$ ). Results are reproduced in Figs. 3 and 4. Figure 3 shows the annual growth rates of capital at risk $R$, of average annual losses $(p X R)$, and of the economic surplus, as a function of local income $Y$. The vertical line shows the current income in New Orleans, and the horizontal line the rate of risk-free economic growth. At very low productivity, the growth in capital at risk $R$ would be $4.6 \%$ per year, i.e. more than twice the rate of risk-free economic growth.

\footnotetext{
${ }^{24}$ This large fraction is due to the fact that large parts of the city are below normal sea level, causing them to stay flooded for weeks after Katrina hit the city. The long duration of the floods amplifies damages to houses and buildings. Furthermore, floods in New Orleans occur through dike failures, leading to high water velocity and large damages (RMS 2005).

${ }^{25}$ With the New Orleans parameters, the output function has a single (global) maximum and there is a unique equilibrium.

${ }^{26}$ It is useful to repeat here that the analysis assumes that early warning and evacuation prevents human losses in case of floods; the only impact consists in economic and asset losses.
} 


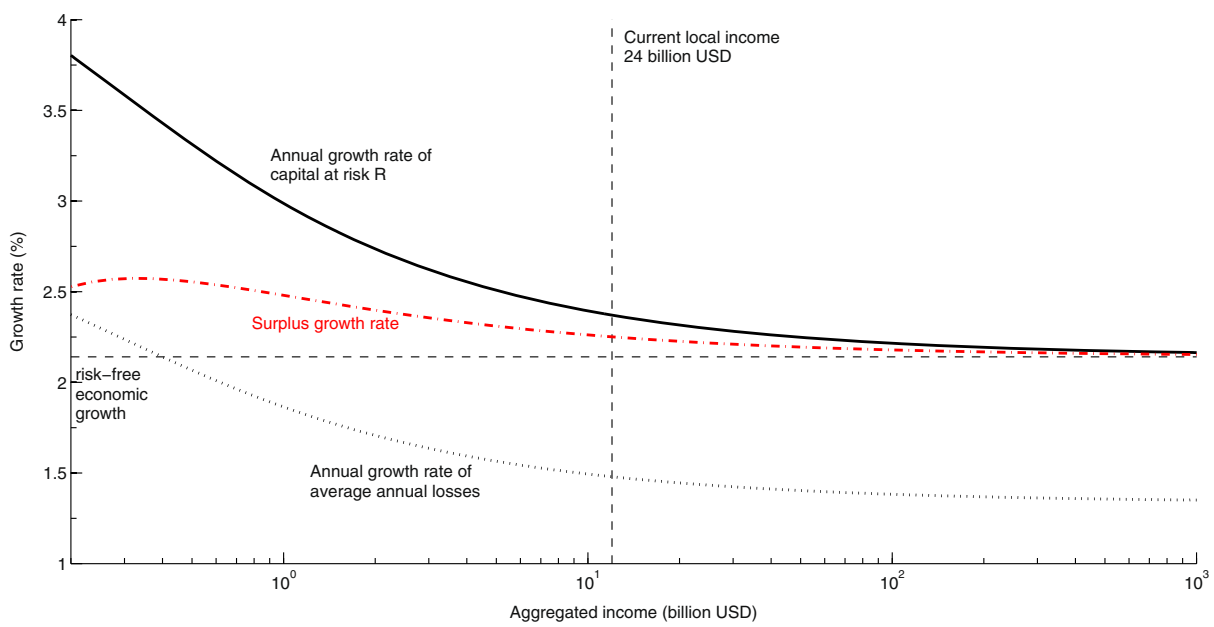

Fig. 3 Annual growth rate of capital at risk $R$, average annual disaster losses, and economic surplus growth rate, as a function of local income. The horizontal line is the rate of risk-free economic growth. Growths in capital at risk and in economic surplus are more rapid than economic growth at early development stage, and these growth rates converge toward economic growth rate over time. Growth in average annual losses is faster than risk-free economic growth at low income levels and slower at high income levels. The vertical dashed line shows the current income in New Orleans

In this situation, the annual probability of flood would exceed $80 \%$ (see Fig. 4). This growth then converges toward the rate of risk-free economic growth (the horizontal dashed line) as development proceeds. The economic surplus growth rate is also larger than the risk-free economic growth rate at a low development level, but converges toward it as development proceeds.

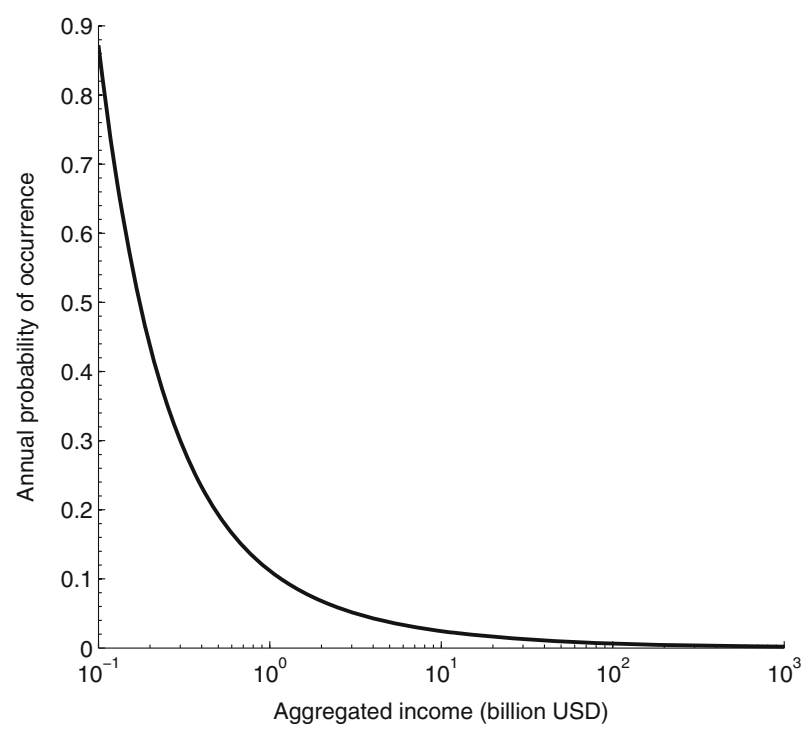

Fig. 4 Optimal disaster probability of occurrence in New Orleans, as a function of local income. Improving protection levels make the probability of occurrence decrease with income 
Figure 2 shows how the fraction at risk - i.e. the fraction of capital located in at risk area - increases with income, assuming $\alpha=2$ (i.e., that in the absence of risk, this fraction would be $38 \%$, according to Eq. 23 ).

For average annual disaster losses, the growth rate is $2.8 \%$ per year at a low development level, i.e. $40 \%$ faster than economic growth. At an income of 40 million USD per year in the city, the growth rate of annual losses is equal to the rate of economic growth $(2.1 \%)$, and this growth rate keeps decreasing until $1.3 \%$ per year, which is economic growth $(2.1 \%)$ corrected by the "protection factor", equal to 0.62 in the case of New Orleans.

In this case, therefore, the income elasticity of average disaster losses would be equal to 0.62 (i.e. a $1 \%$ growth in the US would lead to a $0.62 \%$ growth in average annual losses) and the income elasticity of disaster losses (when a disaster occurs) would be equal to 1.1 (i.e. a $1 \%$ growth in the US would lead a $1.1 \%$-increase in the size of disasters when they occur).

Appendix A proposes an analytical framework to conduct the same analysis in the presence of risk aversion, and provide numerical results in the case of New Orleans. It shows that the qualitative conclusions of this paper are unchanged in the presence of risk aversion, at least within the range of realistic parameter values.

\section{Conclusion}

Taking into account the benefits from risk taking changes the analysis of the trend in disaster economic losses and of risk-reduction policies. In such a framework, economic development allows for better protection and drives the economy toward higher relative exposure to risk (i.e. a growing share of capital is installed in at-risk areas). The overall impact on risk is thus ambiguous and improved protections transfer part of the risk from one kind of risk (frequent and low-cost events) to another kind (exceptional and high-impact events). The increase in relative exposure to risk also accelerates economic growth. Along an optimal growth pathway, increasing exposure is thus both a consequence and a driver of economic development. As a result, indiscriminate policy action to reduce exposure could reduce economic growth and reveal costly.

Current trends in disaster losses appear consistent with what this paper finds as an optimal pathway, namely a trend toward fewer but larger disasters (e.g., Etkin 1999; Nordhaus 2010; Bouwer et al. 2007; Pielke et al. 2008; Bouwer 2011; Schumacher and Strobl 2011; Jongman et al. 2012, 2014). These results are also in line with UN-ISDR (2009), which observes that poor countries suffer from frequent and low-cost events, while rich countries suffer from rare but high-cost events. Of course, it does not mean that current levels of risk taking are optimal or that current trends are sustainable or desirable. As stressed in the introduction, there are many well-identified reasons why risk taking is not optimal, including information and transaction costs, behavioral biases, moral hazards, and other externalities when some actors create risks for others (see a review in World Bank 2013).

But increasing trends in disaster losses - and even trends that are faster than national GDP growth - may be explained by rational behaviors. As such, they are not sufficient to justify public preventive action, beyond risk sharing and support to the affected population. An analysis of the costs and benefits of risk-taking and risk mitigation measures is needed before policies are implemented. Any undiscriminated action to reduce risk (or prevent risk generation) may be counter-productive. For instance, people in at-risk informal settlements in developing country cities settle there because they face a difficult trade-off between living in risky places with good access to jobs and services or to live in safe places without these opportunities (Patankar 2015). Risk reduction policies should not prevent poor people to 
access the opportunities cities can offer. Instead they need to ensure that they can access the same opportunities without being exposed to unacceptable risk levels, for instance through investments in transport systems and public services in safe areas.

Another implication of this paper is that large catastrophes are not going to disappear in the future. Natural disasters are likely to become rarer but also larger, potentially leading to large-scale events that exceed national-level coping capacities. This trend translates into the need for more resilience, i.e. an improved ability to deal with and recover from the rare events that exceed protection capacity (Hallegatte et al. 2017).

Open Access This article is distributed under the terms of the Creative Commons Attribution 4.0 International License (http://creativecommons.org/licenses/by/4.0/), which permits unrestricted use, distribution, and reproduction in any medium, provided you give appropriate credit to the original author(s) and the source, provide a link to the Creative Commons license, and indicate if changes were made.

\section{Appendix A: Taking Into Account Risk Aversion}

To take into account risk aversion, we need to introduce an utility function, which we assume to depend on the economic surplus $u(\pi)$ and to have decreasing returns $u^{\prime}(\pi)>0$ and $u^{\prime \prime}(\pi)<0$. The utility cost of disasters can be approximated by the insurance premium $\delta$ that the region would be ready to pay to avoid all losses, which is defined by:

$$
u\left(\pi_{0}-\delta\right)=p u\left(\pi_{0}-L\right)+(1-p) u\left(\pi_{0}\right)
$$

where $\pi_{0}$ is the surplus in absence of disaster and is equal to $e^{\gamma t} F(R, S)-C(p, R)-r(R+$ $S)$. This equation defines a function $\delta(p, R, S, t)$, which replaces $p X R$ in Eq. 3 when risk aversion is accounted for.

$$
\mathbb{E}[u]=\overbrace{e^{\gamma t} F(R, S)-C(p, R)-r(R+S)-\delta(p, R, S, t)}^{\tilde{\pi}}
$$

And the maximization program becomes:

$$
\begin{gathered}
\max _{p, R, S} \tilde{\pi} \\
\text { s.t. } 0 \leq p \leq p_{0}
\end{gathered}
$$

We use a constant relative risk aversion (CRRA) utility function with the form $u=\frac{\pi^{1-\rho}}{1-\rho}$ :

$$
\delta=\pi_{0}-\left[p\left(\pi_{0}-R X\right)^{1-\rho}+(1-p) \pi_{0}^{1-\rho}\right]^{\left(\frac{1}{1-\rho}\right)}
$$

Since $\delta>p R X$ in presence of positive risk aversion, the taking into account of risk aversion makes perceived risk larger and creates a non-linearity between $R$ and risk. To go further, the optimization program can be solved numerically with the parameters and functional forms from "Numerical Application to New Orleans" on New Orleans, and using the same methodology to calibrate $\lambda$. Since risk aversion introduces total income in the equations of $R$ and $p$, it creates a link between $R$ and $S$ even when the two capitals are separable in the production function. It means that the value of $S$ (i.e. $\alpha$ ) also needs to be calibrated. In practice, the value of $S$ depend on how disaster risks in New Orleans are shared with risk-free capital (or capital that is subject to a risk independent of hurricane risk in New Orleans). As an illustration, equations are solved assuming that $\alpha=2$.

Results for the fraction at risk are presented in Fig. 5, for a risk aversion $\rho=2$. It shows that risk aversion leads to locating less capital in at risk areas, at all development levels. 


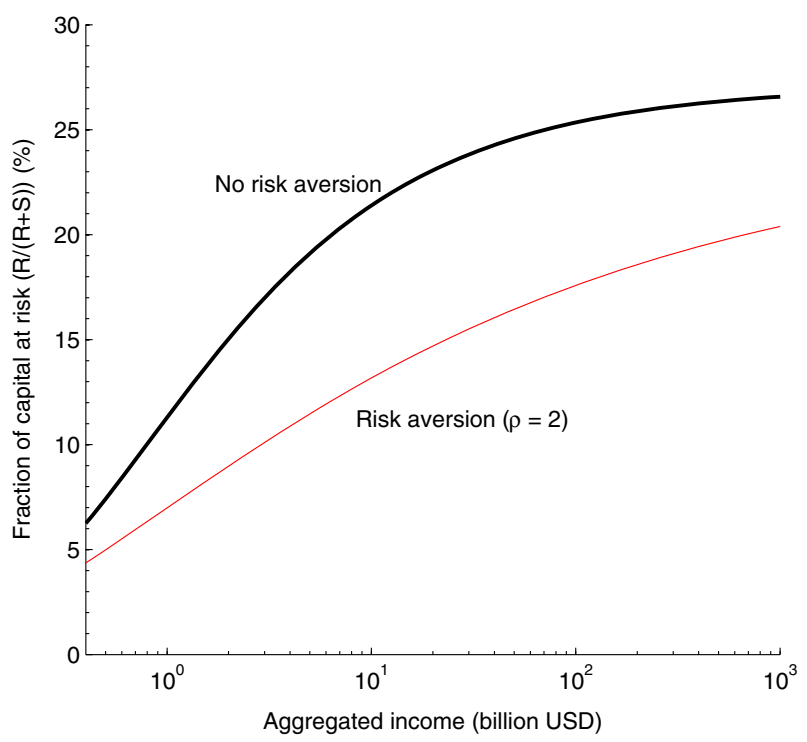

Fig. 5 Evolution of the "fraction at risk", i.e. the share of capital at risk $R$ in total capital $R+S$, as a function of time, with and without risk aversion. Risk aversion reduces the fraction at risk at all development levels. Calculations using numerical values from New Orleans (see "Numerical Application to New Orleans") and $\alpha=2$

Figure 6 shows that risk aversion has an ambiguous impact on the probability of occurrence. This is because risk aversion has two effects on protection: a direct effect through which risk aversion leads to better protection (everything being equal); and an indirect effect through which risk aversion leads to investing less in at-risk areas, which in turn leads to less protection. As a result, risk aversion reduces the protection level and increases the

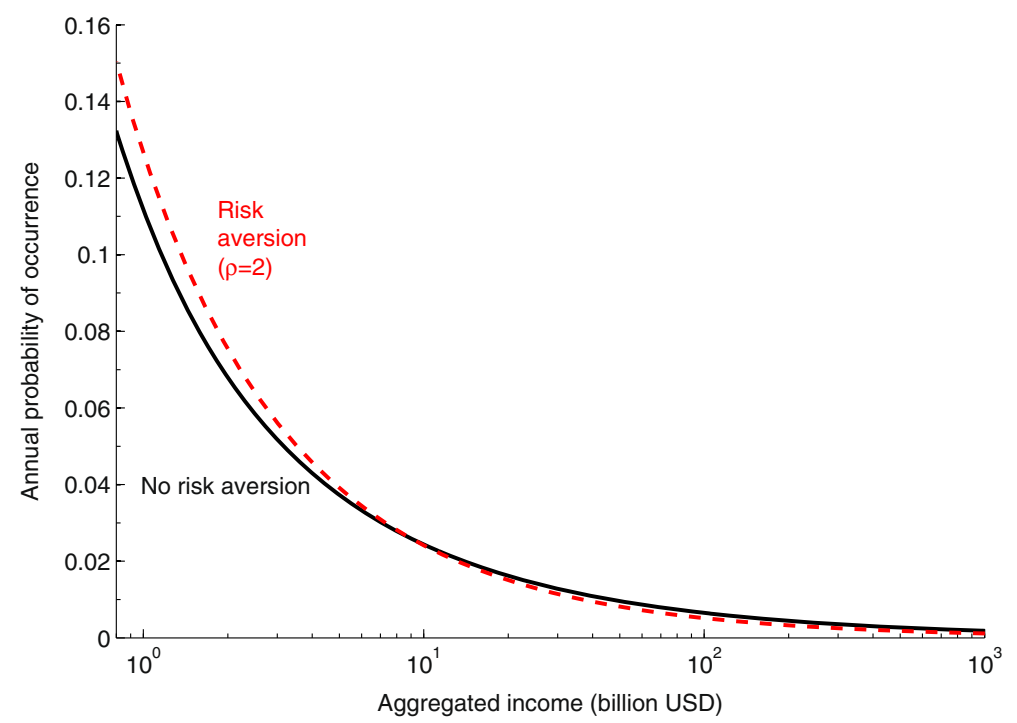

Fig. 6 Evolution of the annual probability of occurrence, without risk aversion and with risk aversion $(\rho=2)$ 


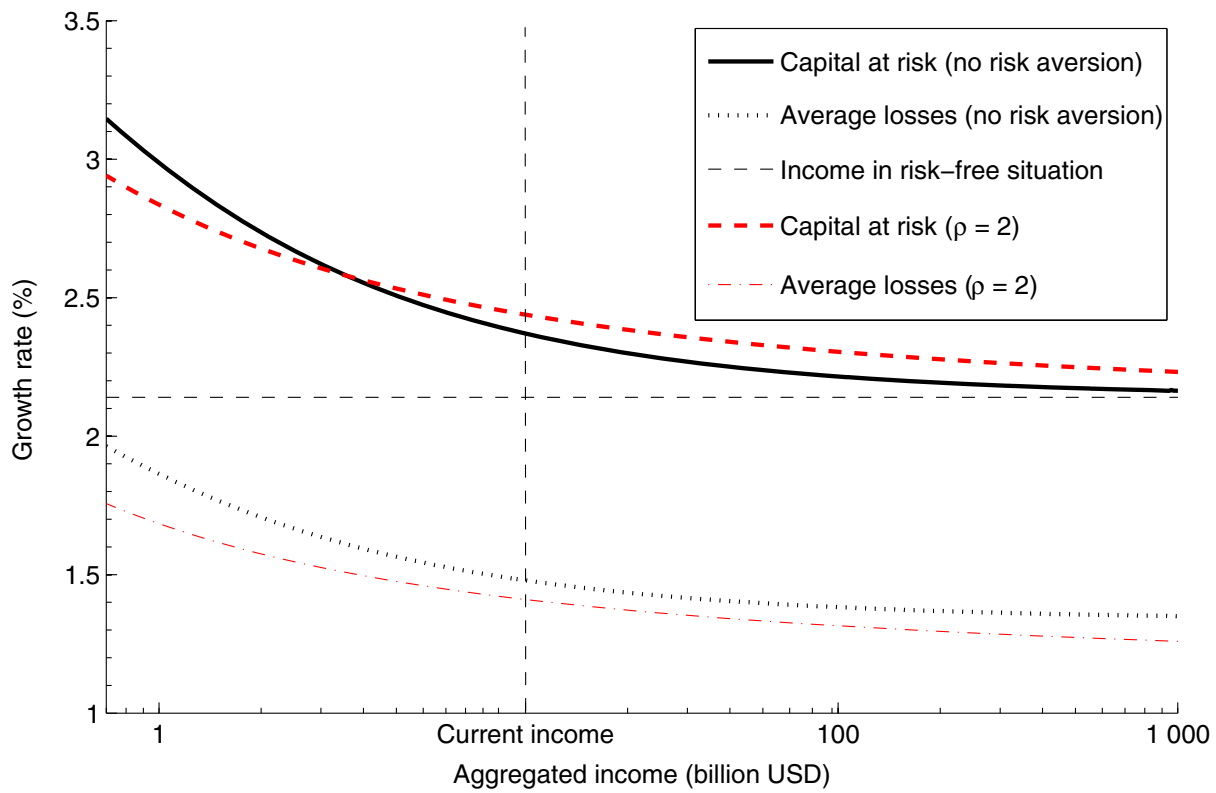

Fig. 7 Evolution of capital at risk $R$ and average annual disaster losses as a function of time, without risk aversion and with risk aversion $(\rho=2)$

probability of occurrence at a low development level. It leads to better protection and to a decrease in the probability of occurrence at a higher development level.

Finally, Fig. 7 shows that capital at risk still grows more rapidly than income at all development levels, and the growth rate converges toward the risk-free growth rate. At high development level and in this simulation, the capital at risk is lower but increases more rapidly with risk aversion than without risk aversion. At a high development level, average annual losses grow at a lower rate than risk-free economic growth, like in the case without risk aversion.

Numerical simulations suggest therefore that the qualitative results in the case without risk aversion remain valid with risk aversion. An exploration of various values of risk aversion $(\rho)$ and of various risk sharing levels (modeled through $\alpha$ here) confirms that results are robust to the presence of risk aversion.

\section{Appendix B: Capital at Risk and Safe Capital as Substituable Inputs in a Cobb-Douglas Function}

If $R$ and $S$ are imperfectly substituable, we can assume that $F(R, S)=\lambda R^{\mu_{1}} S^{\mu_{2}}$. This section demonstrates that this situation is similar to the situation where $R$ and $S$ are separable in the production function.

In this case, the marginal productivity of $S$ gives us:

$$
S=\left(\frac{e^{\gamma t} \lambda \mu_{2}}{r}\right)^{\frac{1}{1-\mu_{2}}} R^{\frac{\mu_{1}}{1-\mu_{2}}}
$$


With $p=\left(\frac{R X}{\nu \xi}\right)^{-\frac{1}{1+\nu}}$, we have:

$$
p X=X\left(\frac{X}{v \xi}\right)^{-\frac{1}{1+v}} R^{-\frac{1}{1+v}}
$$

and the marginal productivity of $R$ gives us:

$$
\lambda \mu_{1}\left(\frac{\lambda \mu_{2}}{r}\right)^{\frac{\mu_{2}}{1-\mu_{2}}} e^{\frac{\gamma t}{1-\mu_{2}}} R^{\frac{\mu_{1}+\mu_{2}-1}{1-\mu_{2}}}=r+X\left(\frac{X}{\nu \xi}\right)^{-\frac{1}{1+\nu}} R^{-\frac{1}{1+\nu}}
$$

Here, we use the same approach as in the main text, and separate low and high development levels.

\section{B.1 Low Development Level}

At a low level of development, and using the same assumptions on $p_{0}, p X$ is larger than $r$, and the equation can be approximated by assuming that $r<<p$, which gives:

$$
R(t)=R_{0} e^{\frac{\gamma}{1-\left(\mu_{1}+\mu_{2}\right)-\frac{1-\mu_{2}}{1+\nu}} t}
$$

So $R$ is increasing if $1-\left(\mu_{1}+\mu_{2}\right)>\frac{1-\mu_{2}}{1+v}$, i.e. if $v>\frac{\mu_{1}+2 \mu_{2}}{1-\mu_{1}-\mu_{2}}$. Using classical values for decreasing capital returns (i.e. $\mu_{1}+\mu_{2} \approx 0.3$ ), and assuming that the capital at risk and the safe capital have the same return convexity, it leads to $v>0.64$, which is the case if protection costs are convex.

Since economic growth in absence of risk would be $\frac{\gamma}{1-\left(\mu_{1}+\mu_{2}\right)}$, the capital at risk increases more rapidly than risk-free economic growth. Average losses $\mathbb{E}[L]=p X R$ are growing at a rate:

$$
\gamma_{L}=\frac{\gamma}{1-\left(\mu_{1}+\mu_{2}\right)-\frac{1-\mu_{2}}{1+v}} \frac{v}{v+1}
$$

Average losses increase more rapidly than risk-free economic growth if:

$$
\frac{\gamma}{1-\left(\mu_{1}+\mu_{2}\right)-\frac{1-\mu_{2}}{1+v}} \frac{v}{v+1}>\frac{\gamma}{1-\left(\mu_{1}+\mu_{2}\right)}
$$

If $R$ is increasing, then the denominator is positive, and this inequality is always verified. So, in this setting, at low levels of development and under mild conditions insuring that the probability of occurrence decreases with time, average disaster losses increase more rapidly than risk-free economic growth.

\section{B.2 High Development Level}

At a high level of development, $p X$ is very small compared with $r$, and the equation can be solved by assuming at $p X=0$ :

$$
R(t)=R_{0} e^{\frac{\gamma}{1-\left(\mu_{1}+\mu_{2}\right)} t}
$$

Which is also the rate of risk-free economic growth. Average losses $\mathbb{E}[L]=p X R$ are then growing at a rate:

$$
\gamma_{L}=\frac{\gamma}{1-\left(\mu_{1}+\mu_{2}\right)} \frac{v}{v+1}
$$


In this case, the growth rate of disaster losses is lower than the rate of risk-free economic growth. Indeed, the growth rate in annual disaster losses is equal to economic growth multiplied by the same "protection factor" $v /(1+v)$ as in the case of a separable production function.

\section{Appendix C: Capital at Risk and Safe Capital are Perfect Substitutes, but with Different Productivity}

If $R$ and $S$ are perfect substitute, the analysis is different. Here, we assume that $R$ and $S$ are the same kind of capital, but they have different productivity: the capital located in at risk areas is more productive than the same capital located in safe areas (if the opposite is true, there is no reason to invest in at risk areas and $R=0)$. It means that $F(R, S)=f(R+\alpha S)$, with $\alpha<1$. Then we have:

$$
\begin{array}{r}
e^{\gamma t} \partial_{R} F(R, S)=e^{\gamma t} f^{\prime}=r+\partial_{R} C+p X \\
e^{\gamma t} \partial_{S} F(R, S)=e^{\gamma t} \alpha f^{\prime}=r
\end{array}
$$

which means:

$$
\frac{1}{\alpha}=\frac{r+\partial_{R} C+p X}{r}
$$

Unless $R=0$ or $S=0$. If both are positive and $C(p, R)=\xi p^{-v}+C_{0}$, then we have $p=\left(\frac{R X}{v \xi}\right)^{-\frac{1}{1+\nu}}$ and $\bar{R}$ defined by:

$$
\begin{gathered}
X\left(\frac{X \bar{R}}{\xi v}\right)^{-\frac{1}{1+v}}=r\left(\frac{1}{\alpha}-1\right) \\
\bar{R}=\left[\frac{1}{r\left(\frac{1}{\alpha}-1\right)}\right]^{(1+v)} X^{v}(\xi v)
\end{gathered}
$$

In this case, $R$ and $p$ are constant, if $R$ and $S$ are non-zero.

If $S=0$, then $R$ grows with time, until it reaches $\bar{R}$. Then, $S$ grows and $R$ remains constant. In such a case, development starts by accumulating capital in at-risk areas, where productivity is higher. But more capital at risk means increased protection. And since protection costs increase non-linearly, the protection cost required to do so increases nonlinearly with time, until the capital marginal productivity adjusted by the protection costs is the same in at-risk areas and in safe areas. Then, development proceeds by accumulating only in safe areas, and the capital at risk and average disaster losses are then constant over time.

This result supports the idea that what matters is the substitution between capital at risk and safe capital and their returns, more than the difference in productivity. Also, it suggests that providing transportation capacities able to make safe and at-risk capitals perfect substitute would cancel the rationale to invest in at-risk areas, and would make it possible to avoid suffering from disaster losses without sacrificing economic growth and income. For instance, people in at-risk informal settlements in developing country cities settle there because they face a difficult trade-off between living in risky places with good access to jobs and services or to live in safe places without these opportunities. They would settle in safe places and reduce flood exposure if better transportation infrastructure and options would connect safe living areas to urban opportunities. Similarly, manufacturing plants are created 
in at-risk coastal areas, but they could be installed in safe areas if transport infrastructure made it possible to ship their production at similar costs. In the broad framework proposed in this paper, transportation investments are risk mitigation investments, when they connect safe areas to the opportunities and amenities that currently exist in risky areas.

\section{References}

Arrow K, Lind R (1970) Uncertainty and the evaluation of public investment decisions. Am Econ Rev 60(3):364-78

Barredo JI (2009) Normalised flood losses in Europe: 1970-2006. Nat Hazards Earth Syst 9:97-104

Bouwer LM, Crompton RP, Faust E, Höppe P, Pielke Jr RA (2007) Confronting disaster losses. Science 318:753

Bouwer LM (2011) Have disaster losses increased due to anthropogenic climate change? Bull Amer Meteor Soc 92:39-46

Burby RJ, Cigler BA, French SP, Kaiser EJ, Kartez J, Roenigk D, Weist D, Whittington D (1991) Sharing environmental risks: how to control governments' losses in natural disasters. Westview, Boulder, CO

Camerer C, Kunreuther H (1989) Decision processes for low probability events: policy implications. J Policy Anal Manage 8:565-592

Carter NT (2005) New orleans levees and floodwalls: hurricane damage protection. CRS report for congress, order code RS22238, September 6, 2005

Ciccone A (2002) Agglomeration effects in Europe. Eur Econ Rev 46(2002):213-227

Ciccone A, Hall RE (1996) Productivity and the density of economic activity. Am Econ Rev 86(1):54-70

Cole S, Gine X, Tobacman J, Topalova P, Townsend R, Vickery J (2013) Barriers to household risk management: evidence from India. Amer Econ J: Appl Econ 5:104-35. doi:10.1257/app.5.1.104

Ehrlich I, Becker GS (1972) Market insurance, self-insurance, and self-protection. J Polit Econ 80:623-648

Elbers C, Gunning JW, Kinsey B (2007) Growth and risk: methodology and micro evidence. World Bank Econ Rev 21:1-20. doi:10.1093/wber/lhl008

Etkin D (1999) Risk transference and related trends: driving forces towards more mega-disasters. Environmental Hazards 1:69-75

Gallup JL, Sachs JD, Mellinger AD (1998) Geography and economic development. National Bureau of Economic Research Working Paper No. 6849

Hallegatte S (2008) An adaptive regional input-output model and its application to the assessment of the economic cost of Katrina. Risk Anal 28(3):779-799

Hallegatte S (2011) How economic growth and rational decisions can make disaster losses grow faster than wealth. Policy Research Working Paper 5617, The World Bank

Hallegatte S, Vogt-Schilb A (2017) Are losses from natural disasters more than just asset losses? the role of capital aggregation, sector interactions, and investment behaviors. World Bank Policy Research Working Paper No. 7885

Hallegatte S, Green C, Nicholls R, Corfee-Morlot J (2013) Flood losses in major coastal cities. Nat Clim Chang 3(9):802-806

Hallegatte S, Vogt-Schilb A, Bangalore M, Rozenberg J (2017) Unbreakable: building the resilience of the poor in the face of natural disasters. World Bank Publication

Hogarth R, Kunreuther H (1995) Decision making under ignorance: arguing with yourself. J Risk Uncertain $10: 15-36$

IPCC (2012) Managing the risks of extreme events and disasters to advance climate change adaptation. In: Field CB, Barros V, Stocker TF, Qin D, Dokken DJ, Ebi KL, Mastrandrea MD, Mach KJ, Plattner G-K, Allen SK, Tignor M, Midgley PM (eds) A special report of working groups i and II of the intergovernmental panel on climate change. Cambridge University Press, Cambridge, UK, and New York, NY, USA, $p 582$

Jongman B, Koks EE, Husby TG, Ward PJ (2014) Increasing flood exposure in the Netherlands: implications for risk financing. Nat Hazards Earth Syst Sci 14:1245-1255

Jongman B, Ward PJ, Aerts JC (2012) Global exposure to river and coastal flooding: long term trends and changes. Glob Environ Chang 22:823-835

Kahn M (2005) The death toll from natural disasters: the role of income, geography, and institutions. Rev Econ Stat 87(2):271-284 
Kellenberg DK, Mobarak AM (2008) Does rising income increase or decrease damage risk from natural disasters. J Urban Econ 63:722-802

King RG (2006) Discretionary policy and multiple equilibria (no. w12076). National Bureau of Economic Research

Kousky C, Luttmer EFP, Zeckhauser RJ (2006) Private investment and government protection. J Risk Uncertain 33:73-100

Kunreuther H, Slovic P (1978) Economics, psychology, and protective behavior. Am Econ Rev 68(2):64-69. Papers and Proceedings of the Ninetieth Annual Meeting of the American Economic Association

Laffont JJ (1995) Regulation, moral hazard and insurance of environmental risks. J Public Econ 58(3):319336

Lewis T, Nickerson D (1989) Self-insurance against natural disasters. J Environ Econ Manag 16:209-223

Loayza N, Olaberria E, Rigolini J, Christiansen L (2009) Natural disasters and growth - going beyond the averages. World Bank Policy Research Working Paper 4980 Washington, DC, World Bank

Mahul O, Ghesquiere F (2007) Sovereign natural disaster insurance for developing countries: a paradigm shift in catastrophe risk financing. World Bank Policy Research Working Paper

Michel-Kerjan E (2010) Catastrophe economics: the national flood insurance program. J Econ Perspect 24(4):165-186

Miller S, Muir-Wood R, Boissonnade A (2008) An exploration of trends in normalized weather-related catastrophe losses. In: Diaz HF, Murnane RJ (eds) Climate extremes and society. Cambridge University Press, Cambridge, pp 225-347

Neumayer E, Barthel F (2010) Normalizing economic loss from natural disasters. A global analysis, Climatic Change, submitted

Nordhaus WD (2010) The economics of hurricanes and implications of global warming. Climate Change Economics 1:1-20

Nordhaus W, Tobin J (1973) Is growth obsolete? The measurement of economic and social performance. National Bureau of Economic Research, Cambridge, MA

Patankar A (2015) The exposure, vulnerability and adaptive capacity of households to floods in Mumbai. Policy Research Working Paper 7481 World Bank, Washington, DC

Pielke RA Jr, Gratz J, Landsea CW, Collins D, Saunders MA, Musulin R (2008) Normalized hurricane damages in the United States: 1900-2005. Nat Hazards Rev 9(1):29-42

Revkin AC, Drew C (2005) Engineers' warnings and pleas for money went unheeded. The New York Times

RMS (2005) Hurricane Katrina: Profile of a Super Cat, Lessons and Implications for Catastrophe Risk Management, available on www.rms.com

Schmidt S, Kemfert C, Höppe P (2009) Tropical cyclone losses in the USA and the impact of climate change: a trend analysis based on data from a new approach to adjusting storm losses. Environ Impact Assess Rev 29:359-369

Schumacher I, Strobl E (2011) Economic development and losses due to natural disasters: the role of hazard exposure. Ecol Econ 72:97-105

Schwartz J (2005) Full flood safety in New Orleans could take billions and decades, The New-York Times, November 29, 2005

Thaler R (1999) Mental accounting matters. J Behav Decis Mak 12:183-206

Tversky A, Kahneman D (1975) Judgment under uncertainty: Heuristics and biases. In: Utility, probability, and human decision making. Springer, Netherlands, pp 141-162

UN-ISDR (2009) Risk and poverty in a changing climate: invest today for a safer tomorrow. United Nations International Strategy for Natural Disaster Reduction Global Assessment Rep. on Disaster Risk Reduction, $207 \mathrm{p}$

UN-ISDR (2011) Revealing risk, redefining development. United Nations International Strategy for Natural Disaster Reduction Global Assessment Rep. on Disaster Risk Reduction, 178 p

Viscusi WK, Aldy JE (2003) The value of a statistical life: a critical review of market estimates throughout the world. J Risk Uncertain 5:5-76

World Bank (2008) Reshaping economic geography. The World Development Report 2009. The World Bank. Washington, DC, USA

World Bank (2013) Risk and opportunity: Managing risk for development. The World Development Report 2014. The World Bank. Washington, DC, USA 